\title{
Bernard Hours, La vertu et le secret. Le dauphin, fils de
} Louis XV

Paris, Honoré Champion, 2006, 408 p., ISBN 2-7453-1437-8, $70 €$.

Didier Boisson

\section{(2) OpenEdition}

\section{Journals}

Édition électronique

URL : https://journals.openedition.org/ahrf/11405

DOI : 10.4000/ahrf.11405

ISSN : 1952-403X

Éditeur :

Armand Colin, Société des études robespierristes

Édition imprimée

Date de publication : 1 mars 2008

Pagination : 209-210

ISSN : 0003-4436

Référence électronique

Didier Boisson, "Bernard Hours, La vertu et le secret. Le dauphin, fils de Louis XV », Annales historiques de la Révolution française [En ligne], 351 | janvier-mars 2008, mis en ligne le 29 décembre 2009, consulté le 03 août 2021. URL : http://journals.openedition.org/ahrf/11405; DOl : https://doi.org/10.4000/ahrf. 11405 


\section{VARIA}

Bernard Hours, La vertu et le secret. Le dauphin, fils de Louis XV, Paris, Honoré Champion, 2006, 408 p., ISBN 2-7453-1437-8, 70€.

Après son étude sur Louis XV et sa cour (PUF, 2002), Bernard Hours nous offre, non pas une biographie, mais davantage un essai sur le dauphin, le fils de Louis XV. Cette recherche présente dès lc départ un double intérêt. D'une part, les travaux sur ce personnage sont rares, la destruction de ses papiers avant de mourir prive l'historien d'une source essenticlle. D'autre part, un peu plus de 10 ans après la mort du dauphin, des ouvrages sont publiés sur le fils de Louis XV par deux ecclésiastiques, Proyart et Griffet, qui vont donner une image reprise couramment par l'historiographic : le dauphin apparait, de 1750 jusqu'à sa mort en 1765 , comme le chef du part dévot à la cour et au conseil, un soutien de la cause jésuite et un adversaire résolu des Lumières. Bernard Hours revient sur cette image.

Concernant les amitiés du prince, ses hagiographes ont souligné que le seul critère était l'attachement à la religion, "le dauphin doit être identifié comme dévot parce qu'il fréquentait des dévots" (p. 63). Toutefois les sources font souvent défaut pour connaître précisément ces amitiés. Plusieurs éducateurs ont, semble-t-il eu une réelle influence : le chevalier de Montaigu, l'abbé de Saint-Cyr; il en est de même de certains menins, le comte du Muy et le duc de La Vauguyon. S'il est également entouré de "prélats intransigeants" comme son précepteur, Jean-François Boyer, Christophe de Beaumont ou Orléans de La Motte, rien ne laisse vraiment supposer que le dauphin soutient leurs prises de position ct qu'ensemble ils forment un réseau. Lecclésiastique dont les liens avec le dauphin sont les mieux connus, est l'évêque de Verdun, Nicolaÿ. Là encore, l'existence d'une "faction » ou d'un parti autour de l'hériticr du trône n'apparaît pas dans la correspondance de cet homme d'Église.

Après sa mort, le dauphin devient un enjeu apologétique entre « les partisans de la religion naturelle ou de sa conciliation avec le christianisme, comme les défenseurs d'une foi imprégnée de transcendance et de grandeur divine (p. 114). Assiduité aux offices religieux, piété affichée, pratique eucharistique régulière, autant de comportements qui, sans être obligatoirement la marque d'un dévot, sont avant tout liés à l'exercice de la fonction royale. Le dauphin cherche en quelque sorte un compromis entre ultramontanisme et gallicanisme, la dévotion du Sacré Coeur en donne un exemple. Enfin, probablement adversaire de toute tolérance religieuse à l'égard des protestants, Louis n'était peut-être pas opposé à une évolution juridique de leur statut, en particulier par la reconnaissance du mariage protestant. Une analyse qui permet donc de fortement nuancer le portrait du prince dévot.

Son entrée au conseil des dépêches date du 23 octobre 1750 et celle au conseil d'État du 13 janvier 1757. Il peut ainsi jouer un rôle politique, surtout après 1757. Qu'cn cst-il réellement? Selon l'historiographie majoritaire, il a été en désaccord profond avec Louis XV. Or, lors de plusieurs crises, en particulier celles du vingtième et du refus de sacrements, il ne semble pas avoir eu d'influence sur les décisions de son père, et il ne paraît pas intervenir pour défendre le clergé. Lecteur de Cardin Le Bret, son principal objectif est de a préserver les prérogatives de la couronne » (p. 185) contre les empiètements des parlements. C'est le cas au 
moment de la suppression des Jésuites. Soutenu par le chancelier Lamoignon, le dauphin aurait davantage souhaité une épreuve de force avec les parlements, alors que le roi ne voulait pas les " heurter de front ". Comme le souligne l'auteur, le prince « visait d'abord à maintenir les prérogatives royales et son intérêt pour la compagnie de Jésus résultait principalement du fait qu'elle servit de cheval de bataille à l'opposition parlementaire " (p. 242).

Concernant la politique internationale, le dauphin ne semble pas avoir eu de réelle influence. Il est ainsi tenu à l'écart des négociations secrètes qui ont abouti au renversement des alliances. Il doit subir les pressions d'un groupe formé, autour de la dauphine Marie-Josèphe de Saxe, pour la défense des intérêts de la Saxe et tout particulièrement les prétentions de son frère Xavier à la couronne polonaise. $\mathrm{Si}$, apparemment, elle ne « semble avoir sollicité du prince une intervention directe » (p. 270), le dauphin n'a pas non plus souhaité se démarquer de la ligne politique définie par le roi et ses ministres.

Ennemi des philosophes et des idées nouvelles? Plusieurs d'entre eux émettent des opinions favorables à l'égard du dauphin, que ce soit Voltaire ou Diderot. Sa bibliothèque se caractérise par la faiblesse des ouvrages religieux et théologiques (moins de $6 \%$ des titres) et la part prépondérante donnée aux livres d'histoire $(40 \%$, dont une part très réduite de l'histoire ecclésiastique) et de sciences et arts (34\%), alors que les belles-lettres ne représentent que $15 \%$ des titres. Aucune prédilection pour le latin, une bibliothèque diversifiée et composée d'ouvrages surtout publiés de son vivant, rien ne permet d'affirmer qu'il est un adversaire résolu des Lumières. Il lit Montesquicu. Il connait les travaux de Quesnay et de Mirabeau, mais "sa philosophie politique, fortement imprégnée des auteurs absolutistes du XVII siècle, apparaît déjà bien obsolète à son époque " (p. 364).

Ainsi, émancipé de toute caricature et de toute littérature hagiographique, Bernard Hours réussit à dégager brillamment un nouveau portrait du dauphin.

Didier Bolsson

André Dangirard, La vie quotidienne en Vendée avant la Révolution. Journal inédit de Dangirard, le « pape " des protestants de La Rochelle (1781), présenté par Alain Gérard, La Roche-sur-Yon, Centre Vendéen de Recherches Historiques, 2005, 304 p., ISBN 2-911253-23-X, $22 €$.

Alain Gérard présente le Journal de mon voyage en Poitou par Pierre Dangirard, un protestant né à la Rochelle en 1725, banquier à Paris puis retiré au pays vers 1760 . Souffrant probablement d'un cancer du colon, ce dernier part à la campagne en 1781 chez des amis au cour du bocage bas-poitevin et il tient la chronique de la vie quotidienne de cette petite communauté réformée.

Lintroduction présente quelques faiblesses : Alain Gérard constate qu'au XVI ${ }^{e}$ siècle, la moitić de la noblesse du Bas-Poitou embrasse la Réforme, mais que le protestantisme sort laminé de la décennie révolutionnaire, pour reconnaître plus loin que le protestantisme a été en réalité décapité par les dragonnades un siècle auparavant. Cherchant à comprendre pourquoi cette région, autrefois marquée par 